\title{
Rural Workers Have Less Access to Paid Sick Days
}

\author{
KRISTIN SMITH AND ANDREW SCHAEFER
}

$\mathrm{J}$

ob flexibility helps workers balance their work and family responsibilities. Central to job flexibility is the ability to take time away from work without losing wages or the threat of being fired. Paid sick days provide job protection to workers and a steady paycheck when they need to care for themselves or family members. ${ }^{1}$ Paid sick days also help workers with more limited resources who cannot otherwise afford to take a day off. To date, however, little research has explored how access to paid sick days varies across place.

Research consistently shows that rural workers have more limited resources, fewer employment options, and face substantial employment barriers compared with urban workers. Rural residents, for example, are more frequently underemployed, have less income growth, and earn less than their metropolitan peers. ${ }^{2}$ Rural workers as a whole also tend to have lower education levels, work fewer hours, and are employed more often in small firms and in the private sector than urban or suburban workers. ${ }^{3}$ Variations in the characteristics of workers and job attributes may be important contributors to differences in access to paid sick days.

This brief analyzes why rural workers have less paid sick time. We use data from the 2008 National Study of the Changing Workforce (NSCW) survey collected by the Families and Work Institute. The NSCW asks respondents whether they have access to at least five paid sick days annually. ${ }^{4}$ With this information, we analyze differences in access by place, demographics, and work related characteristics. Paid sick days, like other job benefits, may be prorated by the number of hours worked per week, which may diminish the chance for parttime workers to receive at least five paid sick days annually. For this reason, we also present analysis of access to paid sick days separately for full-time workers when appropriate.

\section{More Rural Workers Lack Paid Sick Days}

More than four in ten (44 percent) rural workers lack access to paid sick days. In contrast, 34 percent of suburban and 38 percent of central-city workers have fewer than five paid sick

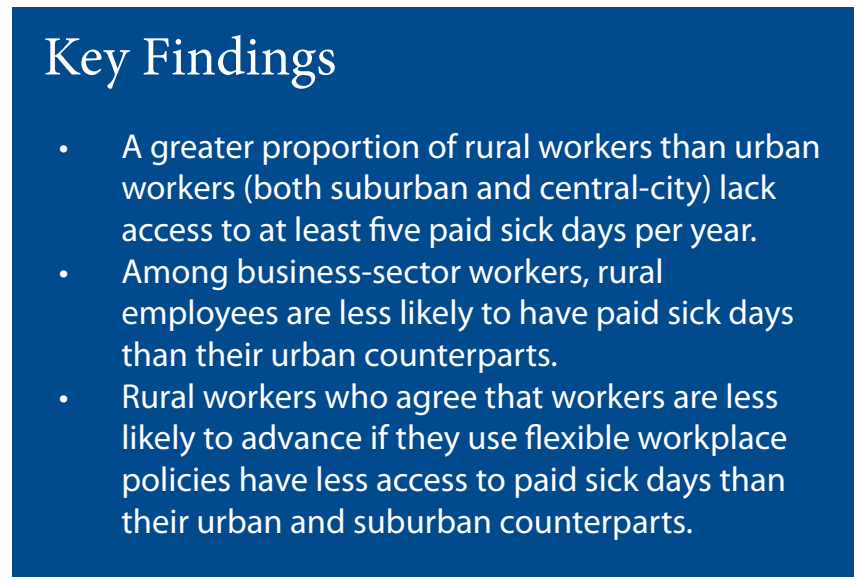

days each year (see Table 1). Likewise, a higher proportion of rural than urban working parents lacks access to at least five days off to care for a sick child without losing pay or having to use vacation time. The proportions without coverage drop somewhat when only full-time workers are included, but the general pattern of a rural disadvantage remains.

\section{Three-Fourths of Rural, Part-Time Workers Lack Paid Sick Days}

One major factor predicting access to paid sick days is whether an individual works full- or part-time hours. Most employment benefits are contingent on full-time employment so part-time workers overall have less paid time off. But rural part-time workers are particularly disadvantaged, with more than three-fourths working without paid sick days (see Figure 1). Even full-time rural workers are less likely to have access to paid sick days than their urban counterparts. It is important to note that, although many workplace benefits are tied to full-time employment, other workplace standards, such as the minimum wage and safety codes, are guaranteed for all workers.

Workers who can ill-afford to forgo a day's pay are often the least likely to have paid sick days. For example, workers with 
Table 1. Percent of WORKers lacking at least fiVe PAID SICK DAYS ANNUALLY BY SELECT CHARACTERISTICS AND PLACE, 2008

\begin{tabular}{lccccc}
\hline & All workers & $\begin{array}{c}\text { Full-time } \\
\text { workers }\end{array}$ & Rural & Suburban & Central city \\
\hline Lack access to: & 38 & 32 & 44 & 34 & 38 \\
$\quad$ Paid sick days & 52 & 48 & 57 & 53 & 46 \\
$\quad$ Paid child sick days & & & & & \\
Education & 45 & 41 & 48 & 41 & 49 \\
$\quad$ High school or less & 42 & 36 & 50 & 39 & 40 \\
Some college & 27 & 20 & 32 & 24 & 28 \\
Bachelor's degree & 18 & 14 & 14 & 20 & 17 \\
More than bachelor's & 18 & & & & \\
Class of worker & 45 & 40 & 54 & 40 & 47 \\
Business sector & 19 & 14 & 12 & 19 & 23 \\
Government sector & 26 & 15 & 37 & 23 & 22 \\
$\quad$ Nonprofit sector & 26 & & & & \\
\hline
\end{tabular}

Note: Includes wage and salaried workers 18 years and older

Source: The 2008 National Study of the Changing Workforce (NSCW) data.

low education levels, who often earn less, are less likely to receive five or more paid sick days annually in both urban and rural locales. Table 1 shows that 45 percent of workers with a high school degree or less lack access to paid sick days compared with 18 percent of those with more than a bachelor's degree. Compared with their urban counterparts, rural workers share similar levels of access to paid sick days by education level, with one exception. Rural workers with some college have lower access than their urban counterparts.

Figure 1. PERCENT OF WORKers LACKING AT LEAST FIVE PAID SICK DAYS ANNUALLY BY WORK HOURS AND PLACE, 2008

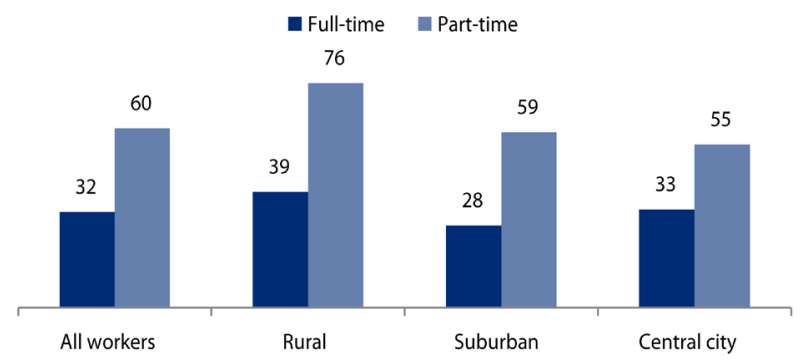

Note: Includes wage and salaried workers 18 years and older. Full-time includes those who work 35 or more hours per week.

Source: The 2008 National Study of the Changing Workforce (NSCW) data.

\section{More Than Half of Rural Business- Sector Workers Lack Access to Paid Sick Days}

Paid sick days are also influenced by other job characteristics, such as employer type. Employees in the business sector are most likely to lack paid sick days, followed by those in the nonprofit sector and, finally, the government sector. This trend is most apparent in rural areas, where more than half of business-sector employees have fewer than five paid sick days per year (compared with
37 percent of nonprofit rural workers and 12 percent of government rural workers). Providing paid sick days may be costly to employers in the short term, but in the long term, paid sick days save employers money by reducing turnover and increasing productivity. ${ }^{5}$

\section{Workplace Culture Is Linked to Access to Paid Sick Days}

Whether an employer offers other job benefits, such as paid vacation days, paid holidays, health insurance, or retirement plan contributions, is consistently correlated with paid sick days. Put another way, workers who lack other job benefits are more likely to also lack paid sick days, particularly in rural areas. For example, 74 percent of rural workers who do not have paid vacation days also lack paid sick days. In contrast, only 35 percent of rural workers who receive paid vacation days lack access to paid sick days (see Figure 2). Access to paid sick days seems to go hand-in-hand with other job benefits.

Figure 2. Percent of WORKers lacking AT LeAst five PAID SICK DAYS BY ACCESS TO PAID VACATION DAYS AND PLACE, 2008

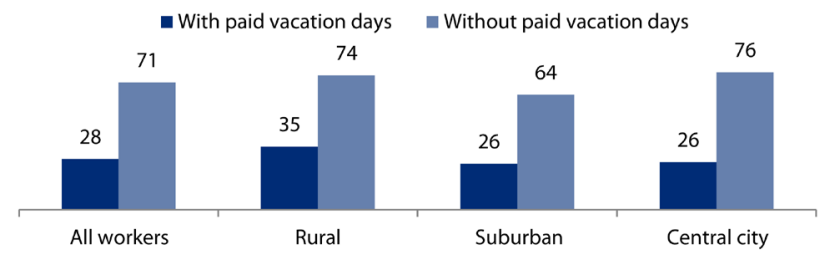

Note: Includes wage and salaried workers 18 years and older.

Source: The 2008 National Study of the Changing Workforce (NSCW) data.

Workplace culture is also correlated with whether workers receive paid sick days. Employees with supportive, "family friendly" workplace cultures are more likely to provide paid sick days. Research finds that supportive workplace cultures have a positive influence on work-life balance and help reduce negative workplace spillover into family life. ${ }^{6}$ In contrast, if the workplace culture looks unfavorably on employees who need or wish to attend to their personal matters, workers will have fewer options when emergencies arise.

Table 2 shows the percent of workers lacking access to paid sick days by the respondents' perception of workplace culture surrounding leave taking. Having paid sick days is correlated with the perception of a workplace that enables the use of flexible policies or time off for family reasons. For example, 52 percent of rural workers who agree that workers in their workplace are less likely to advance if they use flexible workplace policies lack paid sick days. In contrast, only 39 percent of those who disagree lack paid sick days. Rural workers who agree that workers are less likely to advance if they use flexible workplace policies have less access to paid sick days than their suburban but not central city counterparts. A similar pattern 
TABle 2. Percent OF WORKERS LACKING AT LEAST FIVE PAID SICK DAYS BY WORKPLACE PERCEPTIONS AND PLACE, 2008

\begin{tabular}{lcccc}
\hline & $\begin{array}{c}\text { All } \\
\text { workers }\end{array}$ & Rural & Suburban & $\begin{array}{c}\text { Central } \\
\text { city }\end{array}$ \\
\hline People less likely to advance if they use flexible & workplace & policies & & \\
Agree & 46 & 52 & 39 & 50 \\
Disagree & 32 & 39 & 30 & 30 \\
Ability to take leave for personal matters & & & & \\
Very or somewhat difficult & 46 & 54 & 40 & 50 \\
Not difficult & 33 & 39 & 30 & 32 \\
\hline
\end{tabular}

Note: Includes wage and salaried workers 18 years and older.

Source: The 2008 National Study of the Changing Workforce (NSCW) data.

is seen when we consider the relationship between paid sick days and the perception that workers are able to take leave for personal matters. Taken together, Table 2 shows that employees who perceive that their workplace culture is not supportive of leave taking lack access to paid sick days, suggesting that having paid sick days may play a part in creating supportive workplaces.

The findings that rural workers are less likely to have paid sick days could be the result of simply more part-time workers in rural areas or because rural workers tend to have both less education and fewer good jobs with benefits, for example. Therefore, we tease out independent effects of several influential characteristics-place, work hours, employer type, firm size, occupation, job benefits, and workplace flexibility-on paid sick days using multivariete logistic regression. Our analysis also controls for demographic characteristics, such as age, sex, race and ethnicity, marital status, and presence of children. The results confirm the above findings. That is, the rural disadvantage persists; rural workers are 1.5 times more likely to lack paid sick days than suburban workers, independent of the other factors. Even when we restrict the analysis to full-time workers, rural workers are less likely to have paid sick days. This suggests that the rural disadvantage is not due to the greater proportion of part-time workers in rural areas.

Furthermore, our analysis confirms the association between working in the private sector and fewer paid sick days. Rural, private-sector workers were 6.5 times more likely to lack paid sick days than rural government-sector workers. Likewise, a lack of other job benefits and perceptions of workplace flexibility remain strong predictors of rural workers' access to paid sick days, net of the other factors.

\section{Conclusion}

Our analysis suggests that where one works matters, both geographically and by sector. Rural workers have less access to paid sick days. Private-sector and nonprofit employees more often lack paid sick days than government workers. The quality of the job also matters. Workers with good job benefits, such as paid vacation days and paid holidays, health insurance, and pensions, as well as workers with supportive workplace cultures, also are more likely to have paid sick days. Part-time workers lack paid sick days, likely because workplace benefits are tied to full-time employment. Less predictive of access to paid sick days are workers' own demographic characteristics, such as age, race and ethnicity, and marital status.

Paid sick days are a central component of job flexibility for rural and urban workers alike. Everyone gets sick, and the lack of paid sick days can place workers in a bind, especially given that workers who lack paid sick days are also more likely to lack other paid leave options, such as vacation days. They are forced to choose between caring for a sick family member or themselves and losing pay and perhaps even a job. Research has found that two-thirds of workers do not take unpaid sick time when they need it because of the loss of income and, instead, head to work, potentially infecting coworkers. ${ }^{7}$ Many workers believe that taking unpaid sick time places their job in jeopardy, something that no worker wants to do in today's tight labor market. ${ }^{8}$ Furthermore, evidence from San Francisco, which has a paid sick days ordinance, shows that paid sick days did not hurt job growth or the economy of the city, ${ }^{9}$ and two-thirds of employers now support the law. ${ }^{10}$

The lack of paid sick time disproportionately affects rural workers. The rural disadvantage is particularly pronounced among rural private-sector workers and part-time workers, but even rural full-time workers have less access to paid sick days than their urban counterparts. Increasing access to paid sick days for all workers could go a long way to help workers balance their work and family responsibilities.

\section{Data}

This policy brief uses data on paid sick days and work and family characteristics from The 2008 National Study of the Changing Workforce (NSCW) survey collected by the Families and Work Institute. Comparisons presented in the text are statistically significant at the 0.05 level. All estimates are weighted. The measure of paid sick days refers to access to at least five paid sick days annually, rather than any access. Respondents were asked the following question: "Are you allowed at least five days per year of paid time off for personal illness, or not?" The rural measure is based on the U.S. Census Bureau's metropolitan statistical area (MSA) classifications. Those living in MSAs are considered urban if they live in the central city and suburban if they live in areas around the central city. Those not living within a MSA are considered rural. 


\section{ENDNOTES}

1. We use the term "paid sick days" instead of "paid sick leave" because the latter term is often used to refer to longer periods of paid time off, such as those provided under California's paid family and medical leave.

2. Leif Jensen and Eric B. Jensen, "Employment Hardship Among Rural Men," Economic Restructuring and Family WellBeing in Rural America, edited by Kristin E. Smith and Ann R. Tickamyer (University Park: The Pennsylvania State University Press, forthcoming 2011).

3. Based on analysis by the authors, not shown but available upon request.

4. Survey respondents were asked one question about access to paid sick days, "Are you allowed at least five days per year of paid time off for personal illness, or not?" For this reason, our measure of access to paid sick leave refers to access to at least five paid sick days annually. Estimates presented in this brief may be lower than other estimates portraying any access to paid sick days.

5. Heather Boushey et al., "Work-Life Policies for the Twenty-First Century Economy" (Washington, DC: The Mobility Agenda, 2008); Vicky Lovell, "No Time to Be Sick: Why Everyone Suffers When Workers Don't Have Paid Sick Leave" (Washington, DC: Institute for Women's Policy Research, 2004).

6. S. F. Mennino, B. A. Rubin, and A. Brayfield, "Home-toJob and Job-to-Home Spillover: The Impact of Company Policies and Workplace Culture," The Sociological Quarterly, vol. 46, no. 1 (2005): 107-35.

7. Naomi Gerstel and Katherine McGonagle, "Job Leaves and the Limits of the Family and Medical Leave Act: The Effects of Gender, Race, and Family," Work and Occupations, vol. 26, no. 4 (1999): 510-34.

8. Tom Smith, "Paid Sick Days: A Basic Labor Standard for the 21st Century" (Washington, DC: National Opinion Research Center at the University of Chicago and Public Welfare Foundation, 2008).

9. See the Drum Major Institute for Public Policy Website: http://www.drummajorinstitute.org/library/report. php?ID=145.

10. Robert Drago and Vicky Lovell, "San Francisco's Paid Sick Leave Ordinance: Outcomes for Employers and Employees" (Washington, DC: Institute for Women's Policy Research, 2011).

\section{A BOUT THE AUTHORS}

Kristin Smith is a family demographer at the Carsey Institute and research assistant professor of sociology at the University of New Hampshire (kristin.smith@unh.edu).

Andrew Schaefer is a research assistant at the Carsey Institute (apq62@wildcats.unh.edu).

\section{A C K N O W L E D G E E N T S}

The analysis and production of this policy brief was supported by the Ford Foundation. The authors thank Vicki Shabo at the National Partnership for Women and Families; Anna Wadia at the Ford Foundation; Andrea Lindemann at the Center for Law and Social Policy (CLASP); Robert Drago and Kevin Miller at the Institute for Women's Policy Research (IWPR); Rebecca Glauber and Cesar Rebellion at the University of New Hampshire; and Marybeth Mattingly, Jessica Bean, and Curt Grimm at the Carsey Institute for their thoughtful comments and suggestions. In addition, they would like to thank Amy Sterndale and Laurel Lloyd Earnshaw at the Carsey Institute, and Barbara Ray at Hiredpen, for their editorial and production assistance.

\section{ANIVERSITY}

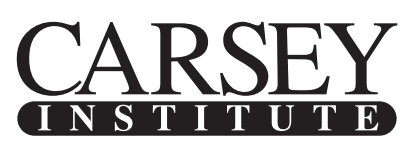

Building knowledge for families and communities

The Carsey Institute conducts policy research on vulnerable children, youth, and families and on sustainable community development. We give policy makers and practitioners timely, independent resources to effect change in their communities.

This work was supported by the Ford Foundation.

Huddleston Hall

73 Main Street

Durham, NH 03824

(603) 862-2821

www.carseyinstitute.unh.edu 